\title{
Effects of social stress during early pregnancy on litter size and sex ratio in the golden hamster (Mesocricetus auratus)
}

\author{
N. C. Pratt* and R. D. Lisk \\ Department of Biology, Princeton University, Princeton, NJ 08544, USA
}

\begin{abstract}
Summary. Primiparous female hamsters were mated to proven breeders and stressed during early pregnancy. Females were housed singly throughout gestation except for Days 4, 5 and 6 when they were paired for 10-min intervals 3 times each day with another female matched for age, weight and day of pregnancy. Within each of the pairs, one female was consistently dominant to the other. Controls were exposed to a novel area instead of a conspecific. At parturition, all pups were counted, sexed and weighed. There were no significant differences between litter sizes or sex ratios (defined as $\%$ male) of control and dominant females. Litter sizes produced by control or dominant dams were significantly larger than those of subordinate dams, and litter sex ratios of dominants were significantly higher than those of subordinates. Subordinate dams produced fewer males than did dominant dams, but there was no difference in the number of females produced. Also, subordinate dams produced smaller pups than control dams. Examination of uterine implantation sites and fetal resorptions indicated that fetal loss occurred between Days 5 and 10 of pregnancy. These results suggest that subordinate dams produce smaller litters via selective resorption or spontaneous abortion of males in utero and that those males they do produce are smaller than those produced by dominant or control dams. We suggest that males are more susceptible in utero to effects of maternal stress in this species, and may require more maternal investment to survive to term.
\end{abstract}

Keywords: golden hamster; social stress; litter size; sex ratio; birth weight

\section{Introduction}

Stress interferes with reproduction in many mammals; empirical evidence suggests that stress can inhibit mating behaviour, ovulation, implantation, fetal growth and lactation (Velardo, 1957; Hagino et al., 1969; Yang et al., 1969; Sod-Moriah, 1971; Christian, 1980; Kittinger et al., 1980). Restraint stress early in pregnancy has been shown to decrease mean litter size in rats (Euker \& Riegle, 1973) and mice (Wiebold et al., 1986). Many studies on the effects of stress on reproductive function have utilized human-imposed stressors, such as shock, restraint, heat and noise, stressors which probably do not have much ecological significance for most species. A great deal of research has focussed on the effects of social stress on reproductive inhibition in reference to population density (see Christian, 1970, 1980). Increased aggressive behaviour among animals at high population densities acts as a stressor, activating adrenocortical activity, and the subsequent degree of reproductive inhibition varies with social rank in species which establish dominance hierarchies (Christian \& Davis, 1964; Christian, 1970). However, few studies have examined the effects of social stress in a species in which crowding probably never occurs in natural populations.

Many reports in the literature describe sex ratio adjustments in several mammalian species which are associated with maternal dominance status, age, parity or diet (see Clutton-Brock \&

*Present address: San Diego Zoo, Research Department, PO Box 551, San Diego, CA 92112-0551, USA. 
lason, 1986). Social subordination was chosen to be the stressor in these experiments because it is relevant to the established theories on facultative adjustment of litter size and sex ratio (see Trivers \& Willard, 1973; McGinley, 1984; Clutton-Brock et al., 1986), and because it is a prudent example of the kinds of stress a solitary, food-hoarding species might encounter in natural populations.

The golden hamster is an ideal model for studying the effects of subordination stress on reproduction since hamsters establish stable dominance hierarchies very quickly and dominant animals will attack subordinates and steal their food hoards (Lawlor, 1963). Females tend to be more aggressive then males, and aggression increases during pregnancy (Wise, 1974). There is a strong correlation between body weight and success in aggressive encounters among female hamsters (Payne \& Swanson, 1970). Littering rates and litter sizes may be reduced among females paired for brief periods with conspecifics, and although olfactory cues alone will induce pregnancy block in mice (Bruce \& Parrott, 1960), direct physical contact is required in the hamster (Huck et al., 1983).

\section{Materials and Methods}

Animals. All hamsters were laboratory-bred descendants of the randomly mated LVG strain obtained from Charles River, Inc. (Wilmington, MA, USA). All subjects were maintained on a $14 \mathrm{~h}$ light (22:00-12:00 h):10 h dark photoperiod in rooms controlled for humidity $(50 \%)$ and temperature $\left(20^{\circ} \mathrm{C}\right)$, and were provided with rodent chow and water ad libitum.

Behavioural testing. Primiparous females, about $275( \pm 15)$ days of age, were mated at $13: 00 \mathrm{~h}(1 \mathrm{~h}$ after lights-off) with proven breeders and placed into one half of a partitioned glass aquarium $(60 \times 30 \times 30 \mathrm{~cm})$. A conspecific (matched for age, weight $( \pm 5 \mathrm{~g})$ and day of pregnancy) was housed on the other side of the removable Plexiglas partition. On Day 4 after the day of mating (Day 0), the partition was lifted for three 10-min intervals at 13:00, 15:00 and 17:00 h, and the pair of animals was allowed to interact freely. Control females were exposed to an empty area on the other side of the partition. This procedure was repeated on Days 5 and 6 .

During the 10-min interactions, aggressive and defensive behaviour were recorded, including attack, chase, and flee (as described by Grant \& Mackintosh, 1963). An animal was classified as dominant if its chase plus attack score was at least 5 times that of the other member of the pair, or at least totalled 10 if the subordinate animal did not attack the other at all. If the agonistic scores from a pair of animals did not meet this criterion the pair was excluded from the data set.

Study 1. After behavioural testing on Day 6, approximately half of the experimental pairs and controls were transferred to plastic breeding boxes $(38 \times 30 \times 17 \mathrm{~cm})$, provisioned with wood shavings, food and water, and left undisturbed until the day of parturition. Dams were checked hourly for signs of parturition beginning $4 \mathrm{~h}$ before lights-out on Day 16. At parturition, all pups were counted, sexed (by measurement of ano-genital distance) and weighed.

Study 2. To determine the stage of pregnancy at which deficits in litter sizes first appeared, the remaining experimental pairs and controls were killed on Day 10 of pregnancy by an overdose of pentobarbitone sodium. Uteri were removed and examined for implantation sites and/or complete (normal-sized) fetuses. Fetal swellings of less than $50 \%$ diameter of the mean size within each uterus were considered to be undergoing resorption.

Statistical analyses. Data on implantation sites, resorptions, litter sizes, sex ratios and pup weights were analysed by non-parametric statistics. For groups showing pregnancy rates of less than $100 \%$, females which produced no litter were not included in the means as zeros. Comparisons between control and dominant females and between control and subordinate females were made by Mann-Whitney two-sample test. Comparisons between dominant and subordinate females were made by Wilcoxon matched-pairs tests. Litter sex biases were analysed by $\chi^{2}$ tests. Correlations between aggression scores and litter sizes, between litter sizes and sex ratios, between litter sizes and pup weights, and between maternal weight and litter sizes or pup weights were made by calculating Spearman rank correlation coefficients.

\section{Results}

\section{Study 1}

Litter sizes and compositions are shown in Table 1. Three subordinate females died after testing and before giving birth.

There were no significant differences between litter sizes produced by control or dominant dams. Subordinate dams produced significantly smaller litters than did control or dominant dams. 
Table 1. Delivery rates and litter compositions (mean \pm s.e.m.) produced by dams of the three experimental groups

\begin{tabular}{lcccccc}
\hline $\begin{array}{l}\text { Status } \\
\text { of dam }\end{array}$ & No. & $\begin{array}{c}\text { No. (\%) } \\
\text { littering }\end{array}$ & $\begin{array}{c}\text { Litter } \\
\text { size }\end{array}$ & $\begin{array}{c}\text { Sex } \\
\text { ratio }\end{array}$ & $\begin{array}{c}\text { No. of } \\
\text { male pups }\end{array}$ & $\begin{array}{c}\text { No. of } \\
\text { female pups }\end{array}$ \\
\hline Control & 31 & $29(94)$ & $11 \cdot 2 \pm 0 \cdot 6$ & $0 \cdot 46 \pm 0.03$ & $5 \cdot 1 \pm 0.4$ & $6 \cdot 1 \pm 0.5$ \\
Dominant & 28 & $28(100)$ & $10 \cdot 8 \pm 0.6$ & $0.50 \pm 0.03$ & $5 \cdot 6 \pm 0.5$ & $5 \cdot 3 \pm 0.3$ \\
Subordinate & 25 & $22(88)$ & $8 \cdot 7 \pm 0.9^{* \dagger}$ & $0.39 \pm 0.04^{*}$ & $3 \cdot 7 \pm 0.5^{*} \dagger$ & $5 \cdot 0 \pm 0.6$ \\
\hline
\end{tabular}

${ }^{*} P<0.05$ compared with dominant dams.

$\dagger P<0.05$ compared with control dams.

There was an all-or-none effect of subordination on litter output, since there was no significant correlation between the number of attacks and chases each subordinate dam received and the subsequent litter size (Spearman $r=0.08 ; P>0.05)$, or the sex ratio $(r=0.08 ; P>0.05)$ she produced.

The sex ratios of litters produced by dominant dams did not differ significantly from those of control dams. However, subordinate females produced significantly lower sex ratios than did dominant females. Subordinate dams produced fewer male pups per litter than did dominant or control dams, but there was no difference in the mean number of female pups produced by the three groups. There was a significant overall effect of maternal status on sex bias of litters produced $\left(\chi_{(4)}^{2}=10.8 ; P<0.05\right)$. Pairwise comparisons showed that the variation was due to differences between sex biases of litters produced by dominant and subordinate dams $\left(\chi_{(2)}^{2}=7 \cdot 3 ; P<0.05\right)$. Subordinate dams produced fewer male-biased litters, more female-biased litters, and more unbiased litters than did dominant dams. There was a significant positive correlation between litter size and sex ratio among litters produced by dominant dams (Spearman $r=+0.53 ; P<0.01$ ), but no such pattern among those produced by control or subordinate dams.

Table 2. Mean ( \pm s.e.m.) pup weights produced by dams of the three experimental groups

\begin{tabular}{lcccc}
\hline $\begin{array}{l}\text { Status } \\
\text { of dam }\end{array}$ & No. & $\begin{array}{c}\text { Pup } \\
\text { weight } \\
(\mathrm{g})\end{array}$ & $\begin{array}{c}\text { Weight of } \\
\text { male pups } \\
(\mathrm{g})\end{array}$ & $\begin{array}{c}\text { Weight of } \\
\text { female pups } \\
(\mathrm{g})\end{array}$ \\
\hline Control & 29 & $2.60 \pm 0.05$ & $2.65 \pm 0.06$ & $2.56 \pm 0.05^{*}$ \\
Dominant & 28 & $2.49 \pm 0.05$ & $2.55 \pm 0.06$ & $2.43 \pm 0.06^{*}$ \\
Subordinate & 22 & $2.41 \pm 0.07 \dagger$ & $2.49 \pm 0.07 \dagger$ & $2.39 \pm 0.07 \dagger$ \\
\hline${ }^{*} P<0.05$ compared with value for male pups. \\
$\dagger P<0.05$ compared with value for control dams.
\end{tabular}

Data on male pup birth weights are shown in Table 2. There were no significant differences between the mean weights of pups produced by control or dominant females. However, subordinate dams produced smaller male and female pups than did control dams. Male pup weight was greater than female pup weight within litters produced by control and dominant dams, but male pups of subordinates were not significantly heavier than female pups. When the data from the three groups were pooled $(\mathrm{N}=84)$, there was no correlation between maternal weight and litter size $(r=0.07 ; P>0.20)$ or mean pup weights produced $(r=-0.12 ; P>0.20)$, nor was there any correlation between litter sizes and mean pup weights $(r=-0 \cdot 18 ; P>0.20)$. Similarly, no correlations were found between these variables when the data were analysed within any of the three experimental groups. 
Study 2

Results from this study are shown in Table 3. By Day 10 of pregnancy, significantly more subordinate dams had experienced some fetal resorption than had control or dominant dams. There was no difference in the number of implantation sites observed between the three groups; however, subordinates showed a significantly reduced mean number of complete fetuses than did control or dominant dams at Day 10. When analysed as a percentage of total number of fetuses implanted, subordinate dams again displayed a significant reduction in the proportion of implantations developing normally at Day 10 compared to control or dominant dams. There was no difference in the amount of fetal loss from the right and the left uterine horns.

Table 3. Incidence of fetal resorptions in 10-day pregnant hamsters paired briefly on Days 4-6

\begin{tabular}{|c|c|c|c|c|}
\hline $\begin{array}{l}\text { Status } \\
\text { of dam }\end{array}$ & No. & $\begin{array}{l}\text { No. }(\%) \\
\text { with fetal } \\
\text { resorptions }\end{array}$ & $\begin{array}{l}\text { Mean } \pm \text { s.e.m. } \\
\text { no. of } \\
\text { implantation } \\
\text { sites }\end{array}$ & $\begin{array}{c}\text { Mean } \pm \text { s.e.m. } \\
\text { no. }(\%) \text { of } \\
\text { "complete } \\
\text { fetuses" }\end{array}$ \\
\hline Control & 18 & $10(55 \cdot 6)$ & $15 \cdot 1 \pm 0.6$ & $\begin{array}{l}14.2 \pm 0.6 \\
(93.9 \pm 1 \cdot 7)\end{array}$ \\
\hline Dominant & 20 & $9(45 \cdot 0)$ & $15.0 \pm 0.5$ & $\begin{array}{c}14 \cdot 0 \pm 0 \cdot 6 \\
(93 \cdot 2 \pm 2 \cdot 4)\end{array}$ \\
\hline Subordinate & 20 & $16(80 \cdot 0)$ & $13.9 \pm 0.5$ & $\begin{array}{l}12 \cdot 1 \pm 0.6 \\
(86 \cdot 3 \pm 2 \cdot 5)^{*} \dagger\end{array}$ \\
\hline
\end{tabular}

${ }^{*} P<0.05$ compared with dominant females.

$\dagger P<0.01$ compared with control females.

\section{Discussion}

The present results suggest that subordinate dams produce smaller litters than do dominant or control dams via selective resorption of male fetuses, since the number of female pups produced does not vary between groups. As litters produced by dominant dams become larger, they become more male-biased, but larger litters produced by subordinates do not become more male-biased. Larger litters are not comprised of smaller pups within any of the groups. The male pups that subordinate dams do produce are smaller than males produced by dominants or controls. However, smaller mothers do not necessarily produce smaller litters, or smaller pups.

The Trivers \& Willard (1973) model for sex ratio adjustment states that, in species with heavy maternal investments, females in poor condition may maximize their reproductive success by producing lower sex ratios, providing that males show a greater variance in reproductive success than do females. If this hypothesis is interpreted in a broad sense, then poor physiological condition can be considered a stressor to the animal, and be caused by a variety of external factors. Males may be more vulnerable to external stressors in utero, perhaps because they are usually larger than females at birth, and require greater maternal investment to survive to term. However, it may also be argued that if males are larger, they may be more resistant to stress. For example, in the European sparrowhawk, in which females are larger than males, there still exists a differential male mortality (Newton, 1986). The same pattern is true for mammals which show reverse size dimorphism (Clutton-Brock et al., 1985). It may not be size per se, which is critical, but the metabolic demands necessary for testosterone production. The hamster fetal testis produces measurable amounts of steroid hormone, but the fetal ovary is quiescent (Clemens \& Witcher, 1985). Gonadectomy before or after puberty in the male hamster leads to an increase in body weight and somatic growth, while 
it has little or no effect on growth in the female, and testosterone administration causes catabolic effects, regardless of food intake or activity (Borer, 1985).

Sundell (1962) karyotyped hamster blastocyst cells immediately before implantation and reported a primary sex ratio of $64 \cdot 3 \%$, but because of differential prenatal mortality, the secondary sex ratio (at parturition) was $50 \cdot 3 \%$. Differential prenatal male mortality is evident in many mammalian species (McMillen, 1979; Clutton-Brock \& Albon, 1982; Trivers, 1985; Clutton-Brock \& Iason, 1986), and reduced sex ratios accompanied by reduced litter sizes have been reported in several species to be correlated with food stress (Rivers \& Crawford, 1974; Labov et al., 1986; Huck et al., 1987), advanced maternal age and/or parity (Huck et al., 1988b) and social subordination (Meikle et al., 1984; Pratt et al., 1989). Differential prenatal male mortality seems to be exaggerated by various forms of maternal stress. As discussed above, this prenatal male mortality may be partly due to the androgen production of the fetal testis, which implies greater metabolic requirements in utero.

In terms of the Trivers-Willard model (Trivers \& Willard, 1973), sex ratio modification by means of sex-differential prenatal mortality may be adaptive if, by producing fewer pups, a stressed female can rear pups which have a high probability of reproducing as adults. Pollard (1986) found that male offspring born to rats stressed daily during pregnancy showed reduced testicular function as adults, whereas female offspring showed no measurable reduction in reproductive function. By giving birth to fewer males, a stressed dam may be able to invest as much in each surviving male offspring as non-stressed dams with larger litters. However, the present study shows that male pups produced by a subordinate dam are smaller at birth than those produced by control dams, so her investment, at least prenatally, is not enough to produce normal sized male offspring at birth. She may be able to 'overinvest' in these males post-natally, to produce male weanlings (of normal size). Weanling data were not recorded in this study, but in another study in the hamster, food-stressed females also produced smaller, more female-biased litters, but did not overcompensate through differential post-partum investment in males (Labov et al., 1986).

Uterine implantation of blastocysts occurs late on Day 4 of pregnancy in the golden hamster (Orsini, 1962), and is greatly dependent on progesterone concentrations (Harper et al., 1969). Progesterone begins to rise on Day 4 of pregnancy and increases steadily until Day 14 when it drops precipitously in advance of parturient activity (Greenwald, 1985). Blastocysts degenerate by Day 5 without ovarian support and there is no delay of implantation in hamsters as in rats or mice (Weitlauf, 1971). It would seem, therefore, that hamsters would be particularly vulnerable to external stressors at this early stage of pregnancy. The present results show, however, that stress applied on Days 4-6 does not interfere with the process of implantation, since in Study 2 subordinate females showed the same number of implantation sites as control or dominant females. When pregnant females were exposed to social stress on Days 2-4, however, there was a significant reduction in the number of implantation sites found in uteri of subordinate females on Day 8 (Huck et al., 1988a). Therefore, implantation had probably already proceeded past a critical point before the stress was applied in the present study.

In the present study, the loss of fetuses occurred some time between Days 5 and 10 of pregnancy, since there was a significant reduction in the number of complete fetuses found in uteri of subordinate females on Day 10 . Subordinate females lost approximately 2 fetuses by Day 10 compared to dominant and control females (see Table 3), and at parturition gave birth to approximately 2 fewer pups than did dominant or control females (see Table 1). Most of the effects of social stress just after implantation were therefore manifested by Day 10 of pregnancy.

Huck et al. (1988a) found that subordinate female hamsters had reduced plasma progesterone concentrations, and that fetal survival varied as a function of progesterone values. Social stress, and other environmental stressors, may interfere with gonadotrophin production or secretion via stimulation of the adrenocortical system in other rodents (Bronson et al., 1973; Ogle, 1977). Since the placenta does not take over the full production of luteotrophic hormones necessary to maintain pregnancy in the hamster (Greenwald, 1985), this species is extremely dependent on the 
neuroendocrine control of gonadotrophin secretion to maintain the integrity of the corpora lutea. Any stress which might activate the adrenocortical system, and thereby interfere with gonadotrophin release, may, indeed, interfere with progesterone production, and therefore cause fetal loss in utero. The present results support this model, but the mechanism by which there is a selective effect on male fetuses is as yet unknown.

This research was supported by National Institutes of Health Training Grant MH 15799 and by the Department of Biology at Princeton University.

\section{References}

Borer, K.T. (1985) Regulation of energy balance in the golden hamster. In The Hamster: Reproduction and Behavior, pp. 363-409. Ed. H. I. Siegel. Plenum Press, New York.

Bronson, F.H., Stetson, M.H. \& Stiff, M.E. (1973) Serum FSH and LH in male mice following aggressive and non-aggressive interactions. Physiol. Behav. 10, 366-372.

Bruce, H.M. \& Parrott, D.M.V. (1960) Role of olfactory sense in pregnancy block by strange males. Science, NY 131, 1526.

Christian, J.J. (1970) Social subordination, population density, and mammalian evolution. Science, $N Y 168$, 84-90.

Christian, J.J. (1980) Endocrine factors in population regulation. In Biosocial Mechanisms of Population Regulation, pp. 5-115. Eds M. N. Cohen, R. S. Malpass \& H. G. Klein. Yale University Press, New Haven.

Christian, J.J. \& Davis, D.E. (1964) Endocrines, behaviour, and population. Science, $N Y 146,1550-1560$.

Clemens, L.G. \& Witcher, J.A. (1985) Sexual differentiation and development. In The Hamster: Reproduction and Behavior, pp. 155-171. Ed. H. I. Siegel. Plenum Press, New York.

Clutton-Brock, T.H. \& Albon, S.E. (1982) Parental investment in male and female offspring in mammals. In Current Problems in Sociobiology, pp. 223-247. Cambridge University Press, Cambridge.

Clutton-Brock, T.H. \& Iason, G.R. (1986) Sex ratio in mammals. Q. Rev. Biol. 61, 339-374.

Clutton-Brock, T.H., Albon, S.E. \& Guinness, F.E. (1985) Parental investment and sex differences in juvenile birds and mammals. Nature, Lond. 313, 131-133.

Clutton-Brock, T.H., Albon, S.E. \& Guinness, F.E. (1986) Great expectations: dominance, breeding success and offspring sex ratios in red deer. Anim. Behav. 34, $460-471$.

Euker, J.S. \& Riegle, G.D. (1973) Effects of stress on pregnancy in the rat. J. Reprod. Fert. 34, 343-346.

Grant, E.C. \& Mackintosh, J.H. (1963) A comparison of the social postures of some common laboratory rodents. Behaviour 21, 246-259.

Greenwald, G.S. (1985) Endocrinology of the pregnant hamster. In The Hamster: Reproduction and Behavior, pp. 53-72. Ed. H.I. Siegel. Plenum Press, New York.

Hagino, N., Watanabe, M. \& Goldzieher, J.W. (1969) Inhibition by adrenocorticotrophin of gonadotrophin-induced ovulation in immature female rats. Endocrinology 84, 308-314.
Harper, M.J.K., Dowd, D. \& Elliott, A.S.W. (1969) Implantation and embryonic development in the ovariectomized-adrenalectomized hamster. Biol. Reprod. 1, 253-257.

Huck, U.W., Bracken, A.C. \& Lisk, R.D. (1983) Femaleinduced pregnancy block in the golden hamster. Behav. Neural Biol. 38, 190-193.

Huck, U.W., Labov, J.B. \& Lisk, R.D. (1987) Foodrestricting first generation juvenile female hamsters (Mesocricetus auratus) affects sex ratio and growth of third generation offspring. Biol. Reprod. 37, 612-617.

Huck, U.W., Lisk, R.D., Miller, K.S. \& Bethel, A. (1988a) Progesterone levels and socially-induced implantation failure in golden hamsters (Mesocricetus auratus). Physiol. Behav. 44, 321-326.

Huck, U.W., Pratt, N.C. \& Lisk, R.D. (1988b) Effects of age and parity on litter size and offspring sex ratio in golden hamsters (Mesocricetus auratus). J. Reprod. Fert. 83, 209-214.

Kittinger, J.W., Gutierrez-Cernosek, R.M., Cernosek, S.F. \& Pasley, T.N. (1980) Effects of adrenocorticotropin on pregnancy and prolactin in mice. Endocrinology 107, 616-621.

Labov, J.B., Huck, U.W., Vaswani, P. \& Lisk, R.D. (1986) Sex ratio manipulation and decreased growth of male offspring of undernourished golden hamsters (Mesocricetus auratus). Beh. Ecol. Sociobiol. 18, 241-249.

Lawlor, M. (1963) Social dominance in the golden hamster. Bull. Br. Psychol. Soc. 16, 1-14.

McGinley, M.A. (1984) The adaptive value of malebiased sex ratios among stressed animals. Am. Nat. 124, 597-599.

McMillen, M.M. (1979) Differential mortality by sex in fetal and neonatal deaths. Science, NY 204, 89-91.

Meikle, D.B., Tilford, B.L. \& Vessey, S.H. (1984) Dominance rank, secondary sex ratio, and reproduction of offspring in polygynous primates. Am. Nat. 124, 173-188.

Newton, I. (1986) The Sparrowhawk. T. \& A.D. Poyser, Ltd, Calton.

Ogle, T.F. (1977) Modification of serum luteinizing hormone and prolactin concentrations by corticotropin and adrenalectomy in ovariectomized rats. Endocrinology 101, 494 497.

Orsini, M.W. (1962) Study of ovo-implantation in the hamster, rat, mouse, guinea pig and rabbit in cleared uterine tracts. J. Reprod. Fert. 3, 288-293.

Payne, A.P. \& Swanson, H.H. (1970) Agonistic behaviour between pairs of hamsters of the same and 
opposite sex in a neutral observation area. Behaviour 36, 259-269.

Pollard, I. (1986) Prenatal stress effects over two generations in rats. J. Endocr. 109, 239-244.

Pratt, N.C., Huck, U.W. \& Lisk, R.D. (1989) Do pregnant hamsters react to stress by producing fewer males? Anim. Behav. 37, 155-157.

Rivers, J.P.W. \& Crawford, M.A. (1974) Maternal nutrition and sex ratio at birth. Nature, Lond. 252 , 297-298.

Sod-Moriah, U.A. (1971) Reproduction in the heatacclimatized rat is affected by high ambient temperature. J. Reprod. Fert. 26, 209-218.

Sundell, G. (1962) The sex ratio before implantation in the golden hamster. J. Embryol. exp. Morph. 10, 58-63.

Trivers, R.L. (1985) Social Evolution. Benjamin Cummings, Menlo Park.

Trivers, R.L. \& Willard, D.E. (1973) Natural selection of parental ability to vary the sex ratio of offspring. Science, NY 179, 90-92.
Velardo, J.T. (1957) Action of adrenocorticotropin in pregnancy and litter size in rats. Am. J. Physiol. 191, 319-322.

Weitlauf, H.M. (1971) Protein synthesis in vivo by preimplantation hamster embryos. Am. J. Anat. 132, 103-107.

Wiebold, J.L., Stanfield, P.H., Becker, W.C. \& Hillers, J.K. (1986) The effects of restraint stress in early pregnancy in mice. J. Reprod. Fert. 78, 185-192.

Wise, D.A. (1974) Aggression in the female golden hamster: effects of reproductive state and social isolation. Horm. Behav. 5, 235-250.

Yang, W.H., Yang, W.P. \& Lin, L.L. (1969) Interruption of pregnancy in the rat by administration of ACTH. Endocrinology 84, 1282-1285.

Received 31 March 1989 